\title{
The prevalence of depression and anxiety among Chinese adults with cancer: a systematic review and meta-analysis
}

\author{
Yi-Long Yang, Li Liu, Yang Wang, Hui Wu, Xiao-Shi Yang, Jia-Na Wang and Lie Wang*
}

\begin{abstract}
Background: A lot of empirical studies have been conducted to evaluate the prevalence of depression and anxiety among Chinese adults with cancer. We aimed to conduct a meta-analysis in order to evaluate the prevalence and odds ratios of depression and anxiety in Chinese adults with cancer compared with those without.

Methods: The three most comprehensive computerized Chinese academic databases-CNKI, Wangfang and Vip databases-were systematically screened through September 2012. PubMed and Web of Science (SCIE) were also searched from their inception until September 2012 without language restrictions, and an internet search was also used. Case-control studies assessing the prevalence of depression and anxiety among Chinese adults with cancer were analyzed. Study selection and appraisal were conducted independently by three authors. The non-weighted prevalence, pooled random-effects estimates of odds ratio (OR) and 95\% confidence intervals (Cl) were all calculated.
\end{abstract}

Results: Seventeen eligible studies with a total of 3497 subjects were included. The prevalence of depression and anxiety were significantly higher in adults with cancer compared with those without (Depression: $54.90 \%$ vs. 17.50\%, $\mathrm{OR}=7.85,95 \% \mathrm{Cl}=5.56-11.07, \mathrm{P}=0.000$; Anxiety: $49.69 \%$ vs. $18.37 \%, \mathrm{OR}=6.46,95 \% \mathrm{Cl}=4.36-9.55, \mathrm{P}=0.000$ ), the same situation was also observed in subgroup of control groups, assessment methods and cancer types. Although no difference of depression was observed in studies utilizing clinical diagnosis compared with self-report, the OR of anxiety in adults with cancer compared with those without was higher in studies utilizing clinical diagnosis $(\mathrm{OR}=8.42,95 \% \mathrm{Cl}=4.83-14.70)$ than self-reports $(\mathrm{OR}=5.83,95 \% \mathrm{Cl}=3.64-9.34)$. The ORs of depression and anxiety in cancer patients compared with disease group (Depression: $\mathrm{OR}=6.03,95 \% \mathrm{Cl}=4.23-8.61$; Anxiety: $\mathrm{OR}=4.40,95 \% \mathrm{Cl}=3.05-6.36$ ) were lower than in those compared with normal group (Depression: $\mathrm{OR}=13.58$, 95\% Cl =6.26-29.46; Anxiety: OR=15.47, 95\% Cl=10.00-23.95).

Conclusions: We identified high prevalence rates of depression and anxiety among Chinese adults with cancer. The findings support that the prevalence of depression and anxiety among adults with cancer should receive more attention in Chinese medical settings.

\section{Background}

Depression and anxiety are psychological and physiological states characterized by a collection of physical, emotional, and behavioral components [1,2]. They are common psychological disorders that can impair healthrelated quality of life (including physical, emotional and

\footnotetext{
* Correspondence: liewang@mail.cmu.edu.cn Department of Social Medicine, School of Public Health, China Medical University, 92 North 2nd Road, Heping District, Shenyang 110001, People's Republic of China
}

(c) 2013 Yang et al.; licensee BioMed Central Ltd. This is an Open Access article distributed under the terms of the Creative Commons Attribution License (http://creativecommons.org/licenses/by/2.0), which permits unrestricted use, distribution, and reproduction in any medium, provided the original work is properly cited. social dysfunction), significantly increase mortality rate and lead to a massive medical costs [3-6].

Cancer is considered as a serious and potentially lifethreatening illness, and even as deadly diseases without treatment (such as some advanced cancers), which has an effect on psychological and physiological states of patients. Unsurprisingly, various studies have demonstrated the high levels of depression and anxiety in cancer patients using a variety of assessment methods. Based on foreign reviews, which mainly included the studies from developed countries like America and UK, the prevalence of 
major depression and depressive symptoms in cancer patients were $0 \%-38 \%$ and $4.5 \%-58 \%$ respectively [7-10]. The prevalence of anxiety varied from $0.9 \%$ to $49 \%$ in one review of 58 studies [10], and the range was narrower (5.1\%-23\%) in large studies using standardized psychiatric interviews $[7,11]$. In China, the prevalence of depression and anxiety in cancer patients were $25.8 \%-58 \%$ and $32 \%-40 \%$ respectively [12-14].

Cancer patients might be vulnerable to depression and anxiety for many reasons: reactions to cancer diagnosis, the presence of unpleasant symptoms associated with cancer (such as pain, nausea and fatigue), and concerns about disease recurrence or progression. Besides, the physiologic effects of certain treatments (such as high-dose interferon therapy, radiotherapy and chemotherapy) also influenced anxiety and depression [15,16]. Cancer patients with depression may present with worthlessness, hopelessness, lose of energy and interest and suicidal preoccupation $[17,18]$. And many cancer patients are also anxious, because anxiety is a response to a threat like cancer $[19,20]$, and anxiety has been shown to frequently coexist with depression $[17,21]$. Sometimes anxiety and depression after cancer diagnosis are adaptive, and may not present a problem. However, some patients continue to have high levels of depression and anxiety that persist for weeks or months, and the untreated anxiety and depression can lead to difficulty with symptom control, hampered treatment decision-making, poor compliance with treatment, prolonged recovery times and impaired quality of life $[9,18,22,23]$.

Nevertheless, evidence is accumulating to suggest that identification and treatment of depression and anxiety among cancer patients will result in reduction in disease progression, improvement in survival rates, reduction in medical costs and improvement in quality of life $[22,24,25]$. Two recent meta-analyses suggested that compared with control group, psychological intervention effectively improved physical and mental condition of Chinese cancer patients [26,27]. Likewise, some systematic reviews suggested that psychological interventions, like cognitive behavioral therapy (CBT), could be effective against anxiety and depression in cancer patients and have good potential for dissemination in routine clinical practice in America $[28,29]$. Psychosocial interventions to treat depression and anxiety were also effective even in patients with advanced cancer $[29,30]$.

It should be noted that before antidepressant/anxiolytic medication, and psychotherapy are performed for cancer patients with psychological disorders, the initial recommendation is for evaluation, diagnostic studies, and correction of factors potentially contributing to psychological disorders [29]. Subsequently, effective interventions and special optimum care could be developed for cancer patients based on these findings. Consequently, the first thing we will do is to evaluate the overall prevalence of depression and anxiety in Chinese adults with cancer before planning treatment provision. Although there are many studies evaluating the level of depression and anxiety in Chinese cancer patients, there are some gaps in literatures. First, some studies did not use a control group. We cannot know the level of depression and anxiety of cancer patients compared with other populations. Second, sample size of individual study assessing psychological distress in cancer patients is usually small. Last, a recent Chinese study used the data from 36 cancer registry sites in China and from Third Chinese Death Cause Survey (accepted by GLOBOCAN 2008) to estimate the incidence and mortality rates of cancers in 2008. The numbers of new cases and deaths from cancer was 2.82 million (22.3\% of world total) and 1.96 million (25.9\%) in China in 2008, and the number will forecast to hit 2.99 million and 2.07 million by 2010, 3.88 million and 2.76 million by 2020 , and 4.87 million and 3.60 million by 2030 [31]. Now there has not been a quantitative review, namely meta-analysis, to assess the prevalence of depression and anxiety in Chinese adults with cancer compared with those without, and this situation is similar to foreign countries. Many foreign reviews of cancer patients with psychological distress were only the qualitative literature reviews $[9,32,33]$ or the included studies of the meta-analysis did not use control group as comparison [7].

Therefore, the present meta-analysis aims to synthesize individual study evaluating depression and anxiety in Chinese adults with cancer, and to assess the prevalence and odds ratio (OR) of depression and anxiety in Chinese adults with cancer compared with those without.

\section{Methods}

\section{Literature search}

A systematic search was conducted to identify published literature on the prevalence of depression and anxiety in Chinese adults with cancer. The CNKI database (China National Knowledge Infrastructure), Wanfang database, and Vip database, which are the three most comprehensive Chinese academic database, were searched from their inception until September 2012. We used 'depression or depressive disorders or depressive symptoms' and 'anxiety or anxiety disorder or anxiety symptoms' combined with 'cancer or oncology or malignant neoplasm or malignant tumour' as search themes in the article titles, abstracts and keywords. The reference lists of relevant articles obtained were also screened.

In order to expand searches, PubMed and Web of Science (SCIE) were searched from their inception until September 2012 without language restrictions, and an internet search was also used (e.g., www.google.com). The search strategy was: (neoplasms[MeSH Terms] OR cancer[Title/Abstract] OR neoplasms[Title/Abstract] OR oncology[Title/Abstract]) AND (China[MeSH] OR China 
[Title/Abstract] or Mainland China[Title/Abstract]) AND (depression $[\mathrm{MeSH}]$ OR depressive disorder [MeSH] OR depression[Title/Abstract] OR depressive disorder [Title/Abstract] OR depressive symptoms[Title/Abstract] OR anxiety[MeSH] OR anxiety disorders[MeSH] OR anxiety[Title/Abstract] OR anxiety disorders[Title/Abstract] OR anxiety symptoms[Title/Abstract]).

The screening of the abstracts/titles and full-text articles were performed twice by three authors (YLY, LL and YW) independently to reduce reviewer bias and errors.

\section{Inclusion and exclusion criteria}

We included all studies in which: (1) the subjects were aged 18 or older; (2) the subjects of cancer group were patients diagnosed with cancer; (3) case-control studies were eligible, including cancer group and non-cancer control group; (4) studies were included to those involving more than 30 adults with cancer; (5) the subjects had a depression and anxiety according to clinical diagnosis as described in DSM-IV (Diagnostic and Statistical Manual of Mental Disorders, Fourth Edition) [34] or CCMD (Chinese Classification of Mental Disorders) [35] or HRSD/HRSA (Hamilton Rating Scale for Depression and Hamilton Rating Scale for Anxiety) [36,37], or the depression and anxiety of both cancer group and control group were identified by self-report questionnaires that previous studies have established the reliability of them as a measure of depression and anxiety at home and abroad; (6) the prevalence of depression and anxiety were both reported in cancer group and control group; (7) the subjects were from Mainland China (Hong Kong and Macao were excluded due to the long-term European influence). We excluded studies in which: (1) the studies only included cancer patients; (2) it was not sure if the control group excluded the cancer patients; (3) depression and anxiety were measured with the self-edited scales in China that are not widely used and accepted at home and abroad. Eligibility judgment and data extraction were recorded and carried out independently by two authors (LL and YW) in a standardized manner. Any disagreements with them were resolved by discussion and the involvement of another author (LW).

\section{Quality assessment}

Although the existing checklists and quality assessment scales in observational studies is controversial [38], the Newcastle-Ottawa Scale for assessing quality of observational and nonrandomized studies was adapted for use [39]. The instrument evaluated observational studies based on three criteria: selection of cases, comparability of study groups and assessment of outcome or exposure. We defined three categories: the study was considered to have high quality (low risk of bias) if it scored seven points or above, studies that scored 1 or zero for selection or zero for comparability or for assessment of outcome or exposure were categorized as having low quality (high risk of bias), studies that scored in between were considered as having medium quality (moderate risk of bias). Any disagreements with raters (LL and YW) were resolved by discussion and the involvement of another author (LW).

\section{Meta-analysis}

\section{Assessment of overall effect size}

The effect size of OR is defined as the ratio of odds (odds = Probability/(1-probability) of depression and anxiety occurring in cancer group compared with non-cancer group. An OR greater than 1 indicates that depression/ anxiety is more likely to occur in cancer group compared with control group, while an OR less than 1 indicates that the depression/anxiety is less likely to occur in cancer group. The pooled random-effects estimates of OR and 95\% confidence intervals (CI) were calculated by standard methods using the inverse variance weighting method, ensuring that the larger more precise estimates were given relatively more weighting, and non-weighted prevalence rates were also calculated. A random effects model was used because it involves the assumption of statistical heterogeneity between studies [40,41]. For zero cell counts, the standard method of adding 0.5 to each cell count was used [42]. Overall effects were analyzed using the statistical software Stata v11.0.

\section{Assessment of heterogeneity}

Heterogeneity was evaluated with the $\mathrm{Q}$ statistic and $\mathrm{I}^{2}$ statistic. The Q statistic is used to assess whether differences in results are compatible with chance alone. If the $\mathrm{p}$ value of $\mathrm{Q}$ statistic is above 0.05 , it indicates that there is no significant heterogeneity [43], but the Q statistic is sensitive to the number of studies [44]. To complement the Q statistics, the $\mathrm{I}^{2}$ statistic which denotes the variance among studies as a proportion of the total variance was also calculated and reported, because $\mathrm{I}^{2}$ is not sensitive to the number of studies [44]. Larger values of $\mathrm{I}^{2}$ show increasing heterogeneity. An $\mathrm{I}^{2}$ of $0 \%$ shows no observed heterogeneity, while $25 \%$ shows low, $50 \%$ moderate, and $75 \%$ high levels of heterogeneity [45].

\section{Subgroup analyses}

When the hypothesis of homogeneity was rejected by the $\mathrm{Q}$ statistic and $\mathrm{I}^{2}$ statistic, subgroup analysis was conducted in order to explore potential moderating factors for heterogeneity [44]. Meanwhile, some studies in our meta-analysis included multiple groups (e.g. liver cancer patients and breast cancer patients were compared with a single control group). Subgroup analysis was also used to make sure that each patient was included only once in different subgroups. In our study, subgroup analyses were conducted for moderating factors, including control groups' type 
(disease control vs. normal control), assessment methods of depression/anxiety (clinical diagnosis vs. self-report questionnaire) and cancer types. However, due to a few of studies (the number is less than or equal to 3 ) separately reporting the OR for depression and anxiety in patients with breast cancer, lung cancer, liver cancer, the subgroup comparison of depression and anxiety in different types of cancer patients were not analyzed.

\section{Assessment of publication bias}

The potential of publication bias of the included studies was first examined by funnel plot symmetry. A funnel plot is a useful graph designed to check the existence of publication bias in meta-analyses. A symmetric funnel shape indicates that publication bias is unlikely, but an asymmetric funnel suggests the possibility of publication bias [46]. However, some authors have argued that visual interpretation of funnel plots is too subjective to be useful
[47]. Then Begg's test and Egger's test were further used to more objectively test for its presence (as implemented in Stata v11) [48,49].

\section{Results}

Study selection

A flowchart describing the inclusion and exclusion process is presented. As shown in Figure 1, we identified the possibly eligible articles through CNKI database $(n=549)$, Wangfang database $(n=642)$ and Vip database $(n=119)$. The titles and abstracts of these possibly eligible papers were respectively studied by the three authors (YLY, LL and $Y W)$, and the full-text articles without duplicates $(n=112)$ were selected for further examination. Based on the full-text of these 112 studies we finally selected 17 studies for the present meta-analysis [50-66]. The most important reasons for exclusion were: did not include non-cancer control group $(n=46)$, did not both report

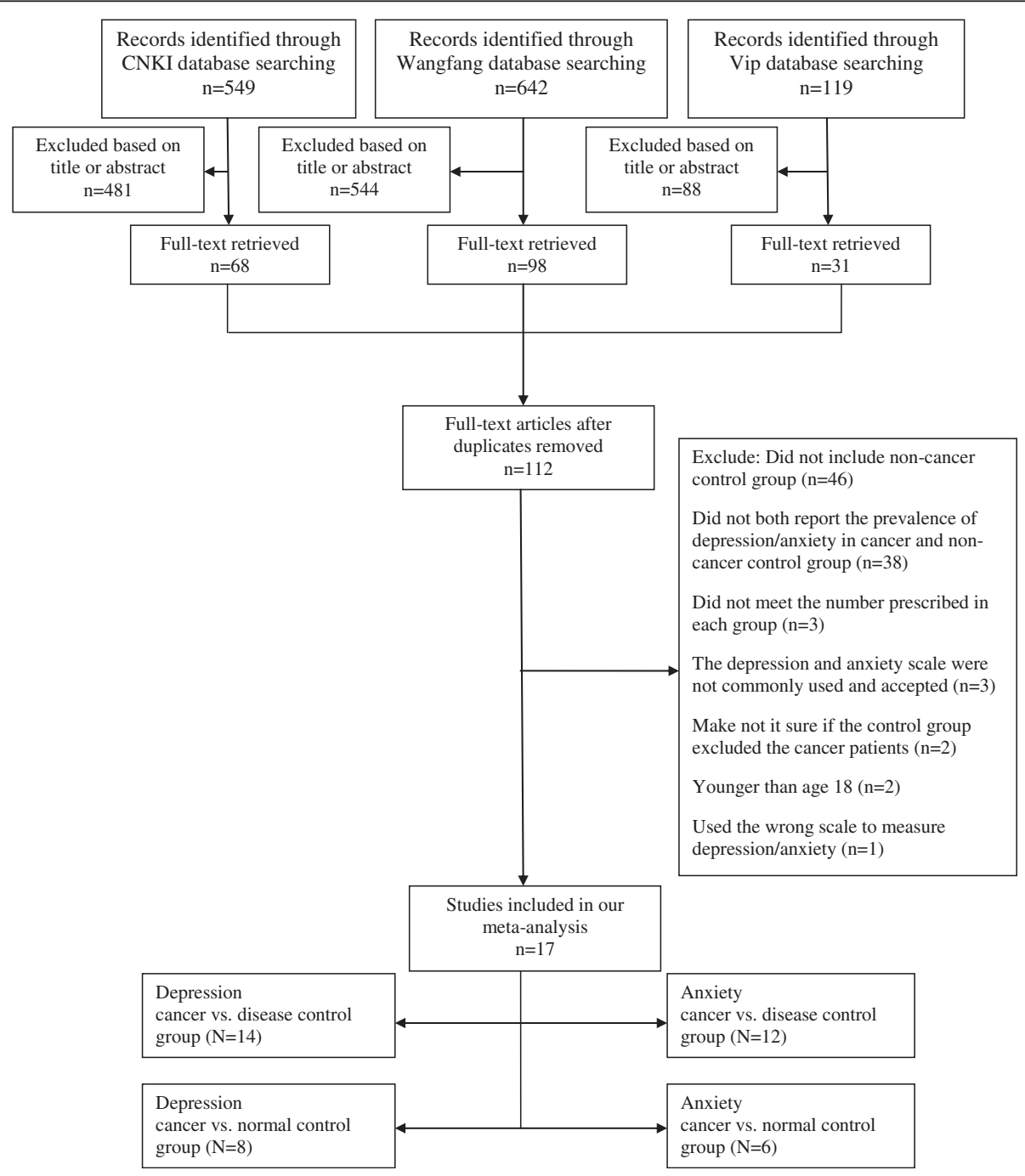

Figure 1 Selection process of studies for the review (Chinese databases). 
the prevalence of depression/anxiety in cancer and non-cancer control group $(\mathrm{n}=38)$. Other reasons included the simple size, the age of subjects, methods of depression and anxiety assessment, and the composition of control group.

In order to expand searches, we also searched the international databases of PubMed, SCIE (as shown in Figure 2), and an internet search (e.g., www.google.com). However, we did not find any literatures that met our inclusion and exclusion criteria through the international databases search.

\section{Characteristics of included studies}

Due to the different types of control groups, the 17 studies with a total of 3497 subjects produced four subgroups: (1) depression in cancer vs. disease control group $(\mathrm{N}=14)$; (2) depression in cancer vs. normal control group $(\mathrm{N}=8)$; (3) anxiety in cancer vs. disease control group $(\mathrm{N}=12)$; (4) anxiety in cancer vs. normal control group $(\mathrm{N}=6)$ (Figure 1). Study characteristics were listed in Table 1. The studies of this meta-analysis, including 15 journal articles and 2 master's theses, were published from 2001 to 2010, except for one in 1989. Of the 17 studies three were conducted among breast cancer patients, three among liver cancer patients (one study included both breast cancer and liver cancer patients), two among lung cancer patients, one among esophageal cancer, one among nasopharynx and liver cancer patients, and other studies among different types of cancers. In all of these studies, in addition to one study of primary liver cancer diagnosed by specialist physician [58], different types of cancer were confirmed by the physicians on the basis of cytologic and pathological diagnosis. Regarding to the disease control group, chronic hepatitis [56,58], diabetes [63], tuberculosis [51], benign tumor [62], and other non-cancer medical patients [50,52,54,55,57,60,61,65] were included. Finally, the levels of depression and anxiety were assessed by clinical diagnosis method in five studies $[50,52,53,64,66]$, while that of the other twelve studies was assessed by self-report questionnaires like Self-rating Depression Scale (SDS) and Self-rating Anxiety Scale (SAS).

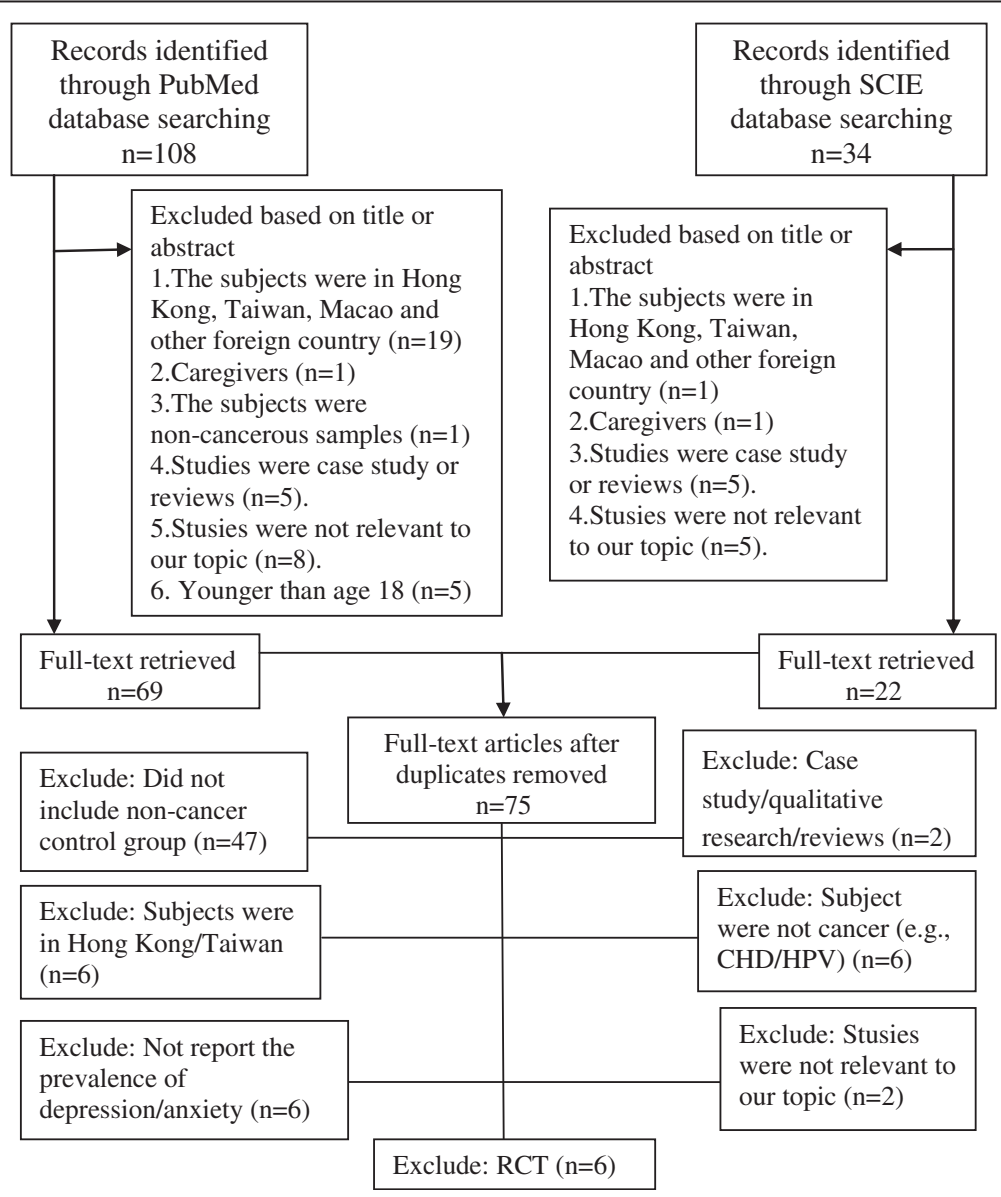

Figure 2 Selection process of studies for the review (international databases). 
Table 1 Characteristics of the included studies

\begin{tabular}{|c|c|c|c|c|c|c|c|c|c|}
\hline Author \& Years & $\begin{array}{l}\text { Depression/ } \\
\text { Anxiety }\end{array}$ & $\begin{array}{l}\text { Participants } \\
\text { (cancer, n) } \\
\text { (control, n) }\end{array}$ & Mean age & Age range & $\begin{array}{l}\text { Depression/Anxiety } \\
\text { assessment method } \\
\text { and cut-off }\end{array}$ & Mean score & Type of cancer & Type of control & $\begin{array}{l}\text { Prevalence of } \\
\text { depression/ } \\
\text { anxiety (\%) }\end{array}$ \\
\hline \multirow[t]{4}{*}{ Yang \& Bao, 2003} & Depression & 96 & 53.67 & $22-76$ & self-report & $47.96 \pm 6.73$ & Mixed & Disease control & 63.5 \\
\hline & & 96 & - & - & (SDS index $\geq 0.5$ ) & $32.32 \pm 5.86$ & & & 17.7 \\
\hline & Anxiety & 96 & 53.67 & $22-76$ & self-report & $49.23 \pm 7.68$ & Mixed & Disease control & 60.4 \\
\hline & & 96 & - & - & (SAS index $\geq 0.5$ ) & $34.06 \pm 5.01$ & & & 13.5 \\
\hline \multirow[t]{2}{*}{ Tang, 2008} & Depression & 150 & 67 & $60-82$ & self-report & - & Mixed & Disease control & 48 \\
\hline & & 50 & - & - & (SDS total score $\geq 11$ ) & - & & & 16 \\
\hline \multirow[t]{4}{*}{ Long et al., 2008} & Depression & 46 & 51 & $36-63$ & self-report & - & Mixed & Disease control & 63.04 \\
\hline & & 50 & 50 & $30-59$ & $(\mathrm{SCL}-90-\mathrm{D}$ mean $\geq 1.5)$ & - & & & 6 \\
\hline & Anxiety & 46 & 51 & $36-63$ & self-report & - & Mixed & Disease control & 89.13 \\
\hline & & 50 & 50 & $30-59$ & $(\mathrm{SCL}-90-\mathrm{A}$ mean $\geq 1.39)$ & - & & & 62 \\
\hline \multirow[t]{8}{*}{ Zhang et al., 2008} & Depression & 60 & 55.9 & $>18$ & self-report & $52.70 \pm 8.70$ & Mixed & Disease control & 73.3 \\
\hline & & 60 & 54.8 & $>18$ & (SDS standard score $\geq 50$ ) & $43.98 \pm 9.35$ & & & 31.7 \\
\hline & Depression & 60 & 55.9 & $>18$ & self-report & $52.70 \pm 8.70$ & Mixed & Normal control & 73.3 \\
\hline & & 60 & 54.8 & $>18$ & (SDS standard score $\geq 50$ ) & $38.43 \pm 7.59$ & & & 8.3 \\
\hline & Anxiety & 60 & 55.9 & $>18$ & self-report & $52.95 \pm 8.35$ & Mixed & Disease control & 70 \\
\hline & & 60 & 54.8 & $>18$ & (SAS standard score $\geq 50$ ) & $45.82 \pm 10.01$ & & & 48.3 \\
\hline & Anxiety & 60 & 55.9 & $>18$ & self-report & $52.95 \pm 8.35$ & Mixed & Normal control & 70 \\
\hline & & 60 & 54.8 & $>18$ & (SAS standard score $\geq 50$ ) & $35.92 \pm 8.04$ & & & 11.7 \\
\hline \multirow[t]{8}{*}{ Tao et al., 2005} & Depression & 72 & 47 & $21-69$ & self-report & $0.54 \pm 0.05$ & $\begin{array}{l}\text { Nasopharynx/ } \\
\text { liver cancer }\end{array}$ & Disease control & 77.8 \\
\hline & & 30 & 43 & $22-65$ & (SDS index $\geq 0.51$ ) & $0.42 \pm 0.06$ & & & 23.3 \\
\hline & Depression & 72 & 47 & $21-69$ & self-report & $0.54 \pm 0.05$ & $\begin{array}{l}\text { Nasopharynx/ } \\
\text { liver cancer }\end{array}$ & Normal control & 77.8 \\
\hline & & 30 & 42 & $23-65$ & (SDS index $\geq 0.51$ ) & $0.39 \pm 0.05$ & & & 10 \\
\hline & Anxiety & 72 & 47 & $21-69$ & self-report & $50 \pm 8$ & $\begin{array}{l}\text { Nasopharynx/ } \\
\text { liver cancer }\end{array}$ & Disease control & 83.3 \\
\hline & & 30 & 43 & $22-65$ & (SAS standard score $\geq 41$ ) & $37 \pm 5$ & & & 40 \\
\hline & Anxiety & 72 & 47 & $21-69$ & self-report & $50 \pm 8$ & $\begin{array}{l}\text { Nasopharynx/ } \\
\text { liver cancer }\end{array}$ & Normal control & 83.3 \\
\hline & & 30 & 42 & $23-65$ & (SAS standard score $\geq 41$ ) & $32 \pm 5$ & & & 13.3 \\
\hline \multirow[t]{2}{*}{ Liu et al., 2001} & Depression & 45 & 59.24 & $24-78$ & clinical diagnosis & $16.78 \pm 7.75$ & Mixed & Normal control & 55.56 \\
\hline & & 45 & - & - & (HRSD total score $\geq 17$ ) & $5.87 \pm 4.67$ & & & 4.44 \\
\hline
\end{tabular}


Table 1 Characteristics of the included studies (Continued)

\begin{tabular}{|c|c|c|c|c|c|c|c|c|c|}
\hline & Anxiety & 45 & 59.24 & $24-78$ & clinical diagnosis & $14.82 \pm 6.51$ & Mixed & Normal control & 46.67 \\
\hline & & 45 & - & - & (HRSA total score $\geq 14$ ) & $6.47 \pm 4.73$ & & & 6.67 \\
\hline \multirow[t]{4}{*}{ Zhang et al., 2009} & Depression & 100 & 58.86 & $35-76$ & clinical diagnosis & $42.46 \pm 12.74$ & Breast cancer & Normal control & 89 \\
\hline & & 100 & - & - & (HRSD total score $\geq 20$ ) & $34.97 \pm 8.31$ & & & 18 \\
\hline & Anxiety & 100 & 58.86 & $35-76$ & clinical diagnosis & $43.24 \pm 10.38$ & Breast cancer & Normal control & 78 \\
\hline & & 100 & - & - & (HRSA total score $\geq 14$ ) & $32.25 \pm 8.26$ & & & 22 \\
\hline \multirow[t]{4}{*}{ Wang et al., 2005} & Depression & 60 & 58 & $34-75$ & self-report & - & Lung cancer & Normal control & 39.58 \\
\hline & & 30 & 51 & $26-68$ & (SDS standard score $\geq 50$ ) & - & & & 10 \\
\hline & Anxiety & 60 & 58 & $34-75$ & self-report & - & Lung cancer & Normal control & 43.75 \\
\hline & & 30 & 51 & $26-68$ & (SAS standard score $\geq 50$ ) & - & & & 6.67 \\
\hline \multirow[t]{4}{*}{ Tian et al., 2005} & Depression & 112 & 55.3 & $36-72$ & self-report & $52.21 \pm 5.61$ & Liver cancer & Disease control & 53.6 \\
\hline & & 152 & 45.6 & $30-60$ & (SDS standard score $\geq 50$ ) & $44.45 \pm 7.66$ & & & 16.4 \\
\hline & Anxiety & 112 & 55.3 & $36-72$ & self-report & $51.1 \pm 4.64$ & Liver cancer & Disease control & 51.8 \\
\hline & & 152 & 45.6 & $30-60$ & (SAS standard score $\geq 50$ ) & $42.99 \pm 7.17$ & & & 24.3 \\
\hline \multirow[t]{8}{*}{ Liu, 2006} & Depression & 124 & 48 & $18-70$ & clinical diagnosis & $16.95 \pm 0.70$ & Mixed & Disease control & 33.26 \\
\hline & & 60 & - & $18-70$ & (HRSD total score $\geq 20$ ) & $6.80 \pm 1.14$ & & & 3.33 \\
\hline & Anxiety & 124 & 48 & $18-70$ & clinical diagnosis & $9.39 \pm 0.51$ & Mixed & Disease control & 29.84 \\
\hline & & 60 & - & $18-70$ & (HRSA total score $\geq 17$ ) & $6.30 \pm 0.83$ & & & 6.67 \\
\hline & Depression & 124 & 48 & $18-70$ & clinical diagnosis & $16.95 \pm 0.70$ & Mixed & Normal control & 33.26 \\
\hline & & 60 & - & $18-70$ & (HRSD total score $\geq 20$ ) & $4.67 \pm 0.92$ & & & 1.67 \\
\hline & Anxiety & 124 & 48 & $18-70$ & clinical diagnosis & $9.39 \pm 0.51$ & Mixed & Normal control & 29.84 \\
\hline & & 60 & - & $18-70$ & (HRSA total score $\geq 17$ ) & $3.63 \pm 0.67$ & & & 1.67 \\
\hline \multirow[t]{4}{*}{ Yuan \& Zheng, 2004} & Depression & 30 & 36.1 & $34-38$ & self-report & $41.83 \pm 12.83$ & Breast cancer & Disease control & 23.3 \\
\hline & & 30 & 35.3 & $25-47$ & (SDS standard score $>53$ ) & $35.63 \pm 6.99$ & & & 0 \\
\hline & Anxiety & 30 & 36.1 & $34-38$ & self-report & $48.93 \pm 13.35$ & Breast cancer & Disease control & 33.3 \\
\hline & & 30 & 35.3 & $25-47$ & (SAS standard score $>50$ ) & $39.30 \pm 9.01$ & & & 3.3 \\
\hline \multirow[t]{4}{*}{ Gao et al., 1989} & Depression & 245 & 46.1 & $20-76$ & self-report & - & Mixed & Disease control & 73.1 \\
\hline & & 232 & 46.4 & $20-74$ & (CES-D total score $\geq 16$ ) & $10.96 \pm 6.46$ & & & 22.5 \\
\hline & Anxiety & 245 & 46.1 & $20-76$ & self-report & - & Mixed & Disease control & 31.1 \\
\hline & & 232 & 46.4 & $20-74$ & (STAl total score $\geq 27$ ) & $13.92 \pm 8.15$ & & & 4.8 \\
\hline \multirow[t]{3}{*}{ Chen \& Gao, 2010} & Depression & 90 & 53.5 & $38-79$ & clinical diagnosis & - & Esophageal cancer & Disease control & 46.7 \\
\hline & & 86 & 51.8 & $36-80$ & (HRSD total score $\geq 20$ ) & - & & & 12.8 \\
\hline & Anxiety & 90 & 53.5 & $38-79$ & clinical diagnosis & - & Esophageal cancer & Disease control & 48.9 \\
\hline
\end{tabular}


Table 1 Characteristics of the included studies (Continued)

\begin{tabular}{|c|c|c|c|c|c|c|c|c|c|}
\hline & & 86 & 51.8 & $36-80$ & (HRSA total score $\geq 7$ ) & - & & & 17.4 \\
\hline \multirow[t]{4}{*}{ She, 2009} & Depression & 142 & 44.53 & $15-82$ & self-report & $50.85 \pm 11.57$ & Mixed & Disease control & 60.6 \\
\hline & & 149 & 44.53 & $15-82$ & (SDS standard score $\geq 50$ ) & $46.09 \pm 12.16$ & & & 38.3 \\
\hline & Anxiety & 142 & 44.53 & $15-82$ & self-report & $47.80 \pm 10.8$ & Mixed & Disease control & 47.2 \\
\hline & & 149 & 44.53 & $15-82$ & (SAS standard score $\geq 50$ ) & $44.51 \pm 10.04$ & & & 23.5 \\
\hline \multirow[t]{8}{*}{ Zhao et al., 2001} & Depression & 65 & 51.5 & $29-71$ & self-report & $0.54 \pm 0.08$ & Liver cancer & Disease control & 43.08 \\
\hline & & 65 & - & - & (SDS index $\geq 0.5$ ) & $0.27 \pm 0.12$ & & & 9.23 \\
\hline & Anxiety & 65 & 51.5 & $29-71$ & self-report & $36.86 \pm 6.47$ & Liver cancer & Disease control & 24.62 \\
\hline & & 65 & - & - & (SAS standard score $\geq 50$ ) & $27.1 \pm 9.76$ & & & 13.69 \\
\hline & Depression & 65 & 51.5 & $29-71$ & self-report & $0.41 \pm 0.09$ & Breast cancer & Disease control & 20 \\
\hline & & 65 & - & - & (SDS index $\geq 0.5$ ) & $0.27 \pm 0.12$ & & & 9.23 \\
\hline & Anxiety & 65 & 51.5 & $29-71$ & self-report & $44 \pm 8.36$ & Breast cancer & Disease control & 20 \\
\hline & & 65 & - & - & (SAS standard score $\geq 50$ ) & $27.1 \pm 9.76$ & & & 13.96 \\
\hline \multirow[t]{4}{*}{ Wan et al., 2004} & Depression & 100 & 44.51 & $20-70$ & self-report & $15.06 \pm 11.5$ & Primary liver cancer & Disease control & 49 \\
\hline & & 100 & - & - & (CES-D total score $\geq 16$ ) & $11.03 \pm 15.06$ & & & 27 \\
\hline & Depression & 100 & 44.51 & $20-70$ & self-report & $15.06 \pm 11.5$ & Primary liver cancer & Normal control & 49 \\
\hline & & 100 & - & - & (CES-D total score $\geq 16$ ) & $8.08 \pm 8.44$ & & & 17 \\
\hline \multirow[t]{2}{*}{ Zhang et al., 2003} & Depression & 155 & - & $>18$ & Clinical diagnosis & $21 \pm 9$ & Lung cancer & Normal control & 43.2 \\
\hline & & 155 & - & $>18$ & (HRSD total score $>8$ ) & $9 \pm 4$ & & & 16.1 \\
\hline
\end{tabular}

Abbreviations: SDS self-rating depression scale, SAS self-rating anxiety scale, SCL-90-D symptom checklist 90-depression, SCL-90-A, symptom checklist 90-anxiety, HRSD hamilton rating scale for depression, HRSA hamilton rating scale for anxiety, CES-D center for epidemiologic studies depression scale, STAl state-trait anxiety inventory; -, no report. 


\section{Risk of bias assessment}

Ratings of study quality for each of the NewcastleOttawa criteria were presented in Table 2. As shown in Table 2, higher scores reflect the better study quality, and the average scores of all studies were above 5 . Seven studies were judged to have low quality for selection of cases or assessment of outcome or exposure and two of high quality; other studies were rated as medium quality.

Prevalence rates of depression and anxiety in cancer patients As shown in Table 3, the overall prevalence of depression and anxiety was higher in adults with cancer compared with those without $(\mathrm{P}<0.001)$. This finding was consistent when the prevalence was determined by control groups, method of depression/anxiety assessment and cancer types $(\mathrm{P}<0.001)$.

The overall prevalence of depression and anxiety were $54.6 \%$ and $49.69 \%$ in Chinese adults with cancer, and the prevalence of depression and anxiety were $18.37 \%$ and $17.50 \%$ in non-cancer group. This prevalence of depression was higher in studies utilizing self-reports than in studies using clinical diagnosis among cancer patients (58.11\% vs. $47.49 \%, \mathrm{P}=0.000)$, and the same situation was also observed among control group (19.65\% vs. $11.90 \%, \mathrm{P}=0.000)$. Meanwhile, the prevalence of anxiety was also higher in self-reports than in clinical diagnosis among cancer patients $(51.74 \%$ vs. $44.93 \%, \mathrm{P}=0.012)$, and the same situation was observed among control group (20.27\% vs. $12.82 \%, \mathrm{P}=0.002$ ).

Odds ratios of depression and anxiety in cancer patients A pooled random effects meta-analysis was conducted using data from 17 studies, which estimated the levels of depression and anxiety in adults with cancer compared with those without. This analysis included data for 1,711 adults with cancer and 1,740 without cancer. As shown in Figures 3 and 4, the odds of depression was associated with a 7.85-fold increased risk of cancer patients when compared with control group $(\mathrm{OR}=7.85,95 \% \mathrm{CI}=5.58$ 11.07; $\mathrm{p}=0.000$ ), and the odds of anxiety was also more than six times as high in cancer patients compared with control group $(\mathrm{OR}=6.46,95 \% \mathrm{CI}=4.36-9.55 ; \mathrm{p}=0.000)$. However, the heterogeneity analysis of the effect sizes of depression $\left(\mathrm{Q}=78.36, \mathrm{p}=0.000 ; \mathrm{I}^{2}=73.2 \%\right)$ and anxiety $\left(\mathrm{Q}=61.21, \mathrm{p}=0.000 ; \mathrm{I}^{2}=72.2 \%\right)$ showed that there was a relatively high amount of heterogeneity in our meta-analysis.

\section{Subgroup analyses}

As shown in Table 4, the ORs of depression and anxiety were significantly increased in adults with cancer compared with those without on moderating factors, including the subgroup of control groups, assessment methods of depression/anxiety and cancer types. The ORs of depression and

Table 2 Assessment of study quality

\begin{tabular}{|c|c|c|c|c|c|c|c|c|c|c|}
\hline \multirow[t]{2}{*}{ Studies } & \multicolumn{10}{|c|}{ Quality Indicators from Newcastle-Ottawa scale } \\
\hline & 1 & 2 & 3 & 4 & $5 A$ & $5 B$ & 6 & 7 & 8 & Total score \\
\hline Yang \& Bao, 2003 & Yes & No & No & Yes & Yes & Yes & No & Yes & No & 5 \\
\hline Tang, 2008 & Yes & No & No & Yes & Yes & Yes & No & Yes & No & 5 \\
\hline Long et al., 2008 & Yes & No & No & Yes & Yes & Yes & No & Yes & No & 5 \\
\hline Zhang et al., 2008 & Yes & No & Yes & Yes & Yes & Yes & No & Yes & No & 6 \\
\hline Tao et al., 2005 & Yes & No & Yes & Yes & Yes & Yes & No & Yes & No & 6 \\
\hline Liu et al., 2001 & Yes & No & Yes & Yes & Yes & Yes & Yes & Yes & No & 7 \\
\hline Zhang et al., 2009 & Yes & No & Yes & Yes & Yes & Yes & No & Yes & No & 6 \\
\hline Wang et al., 2005 & Yes & No & Yes & Yes & Yes & Yes & No & Yes & No & 6 \\
\hline Tian et al., 2005 & Yes & No & No & Yes & Yes & Yes & No & Yes & No & 5 \\
\hline Liu, 2006 & Yes & No & Yes & Yes & Yes & Yes & Yes & Yes & No & 7 \\
\hline Yuan \& Zheng, 2004 & Yes & No & No & Yes & Yes & Yes & No & Yes & No & 5 \\
\hline Gao et al., 1989 & Yes & No & No & Yes & Yes & Yes & No & Yes & No & 5 \\
\hline Chen \& Gao, 2010 & Yes & No & No & Yes & Yes & Yes & No & Yes & No & 5 \\
\hline She, 2009 & Yes & No & No & Yes & Yes & Yes & No & Yes & Yes & 6 \\
\hline Zhao et al., 2001 & Yes & No & No & Yes & Yes & Yes & No & Yes & Yes & 6 \\
\hline Wan et al., 2004 & Yes & No & Yes & Yes & Yes & Yes & No & Yes & No & 6 \\
\hline Zhang et al., 2003 & Yes & No & Yes & Yes & Yes & Yes & Yes & Yes & No & 7 \\
\hline
\end{tabular}

Abbreviations: 1 indicates cases independently validated; 2, cases are representative of population; 3, community controls; 4 , controls have no history of cancer; $5 \mathrm{~A}$, study controls for age/gender; $5 \mathrm{~B}$, study controls for additional factor(s); 6 , ascertainment of depression/anxiety by blinded structured interview or secure record; 7, same method of ascertainment used for cases and controls; and 8, nonresponse rate the same for cases and controls. 
Table 3 Unadjusted prevalence of depression and anxiety in adults with and without cancer

\begin{tabular}{|c|c|c|c|c|}
\hline & No. of studies & No. of subjects & Cancer subjects (\%) & Non-cancer subjects (\%) \\
\hline Depression (All) & 17 & 3484 & $54.90^{* * *}$ & 17.50 \\
\hline \multicolumn{5}{|l|}{ Control group } \\
\hline Disease control & 13 & 2554 & $54.84^{* * *}$ & 19.61 \\
\hline Normal control & 8 & 1286 & $55.03^{* * *}$ & 12.98 \\
\hline \multicolumn{5}{|l|}{ Method of depression assessment } \\
\hline Clinical diagnosis & 5 & 1010 & $47.49^{* * *}$ & 11.90 \\
\hline Self-report questionnaire & 12 & 2474 & $58.11^{* * *}$ & 19.65 \\
\hline \multicolumn{5}{|l|}{ Cancer type } \\
\hline Breast cancer & 3 & 380 & $55.90^{* * *}$ & 12.97 \\
\hline Lung cancer & 2 & 400 & $42.33^{* * *}$ & 15.14 \\
\hline Liver cancer & 3 & 794 & $49.34^{* * *}$ & 17.99 \\
\hline Anxiety (All) & 14 & 2684 & $49.69^{* * *}$ & 18.37 \\
\hline \multicolumn{5}{|l|}{ Control group } \\
\hline Disease control & 11 & 2154 & $46.64^{* * *}$ & 20.30 \\
\hline Normal control & 6 & 786 & $57.27^{* * *}$ & 12.00 \\
\hline \multicolumn{5}{|c|}{ Method of depression assessment } \\
\hline Clinical diagnosis & 4 & 650 & $44.93^{* * *}$ & 12.82 \\
\hline Self-report questionnaire & 10 & 1974 & $51.74^{* * *}$ & 20.27 \\
\hline \multicolumn{5}{|l|}{ Cancer type } \\
\hline Breast cancer & 3 & 390 & $58.46^{* * *}$ & 16.41 \\
\hline Lung cancer & 1 & 90 & $43.33^{* * *}$ & 6.67 \\
\hline Liver cancer & 2 & 394 & $41.81^{* * *}$ & 21.20 \\
\hline
\end{tabular}

*** Prevalence of depression and anxiety significantly greater in patients with cancer compared with a non-cancer control group $(\mathrm{P}<0.001)$. Note: The No. of studies per row is based on the independent group of cancer vs. control group. However, some studies included multiple control groups (e.g., disease and normal control). Thus, the total No. of studies per subgroup of control group is higher than the total number of the included studies in our meta-analysis.

anxiety in cancer patients compared with disease control group (Depression: $\mathrm{OR}=6.03,95 \% \mathrm{CI}=4.23-8.61, \mathrm{I}^{2}=$ 65.5\%; Anxiety: $\mathrm{OR}=4.40,95 \% \mathrm{CI}=3.05-6.36, \mathrm{I}^{2}=61.6 \%$ ) were lower than in those compared with normal control group (Depression: $\mathrm{OR}=13.58,95 \% \mathrm{CI}=6.26-29.46, \mathrm{I}^{2}=$ 79.7\%; Anxiety: $\mathrm{OR}=15.47,95 \% \mathrm{CI}=10.00-23.95, \mathrm{I}^{2}=0 \%$ ).

ORs were also obtained for studies using different methods of depression and anxiety assessment. Although no difference of depression was observed in studies utilizing clinical diagnosis compared with self-report, a significant smaller OR of anxiety was observed in studies utilizing self-reports $\left(\mathrm{OR}=5.83,95 \% \mathrm{CI}=3.64-9.34, \mathrm{I}^{2}=75.4 \%\right)$ compared with clinical diagnosis $(\mathrm{OR}=8.42,95 \% \mathrm{CI}=$ 4.83-14.70, $\mathrm{I}^{2}=36.6 \%$ ).

Due to the small number of studies, the subgroup comparison of depression and anxiety in different types of cancer patients were not analyzed.

\section{Publication bias}

Visual inspection of the funnel plot indicated some publication bias, and the Begg's test and Egger's test further suggested publication bias in depression (Begg's test,
$\mathrm{P}=0.021$; Egger's test, $\mathrm{P}=0.019)$ and anxiety (Begg's test, $\mathrm{P}=0.15$; Egger's test, $\mathrm{P}=0.017$ ) in our meta-analysis.

\section{Discussion}

At the beginning of discussion, we would assess the heterogeneity and study quality in the present meta-analysis. First, we performed strict inclusion criteria, random effects models and subgroup analyses to control and reduce the heterogeneity. However, the heterogeneity was still relatively higher, and the conclusion should be considered with some caution. Second, the Newcastle-Ottawa Scale was used to assess the study quality. We only identified two high-quality studies. The bias of medium-quality and low-quality studies mainly included selection of cases and assessment of outcome or exposure. Quality assessment indicated some methodological weaknesses, which could weaken the internal validity.

The overall prevalence of depression and anxiety in Chinese patients with cancer were 54.9\% (range: 20\%-89\%) and $49.69 \%$ (range: $20 \%-89.13 \%$ ) in our meta-analysis, suggesting that depression and anxiety also did coexist in Chinese cancer patients, similar to this situation in foreign 


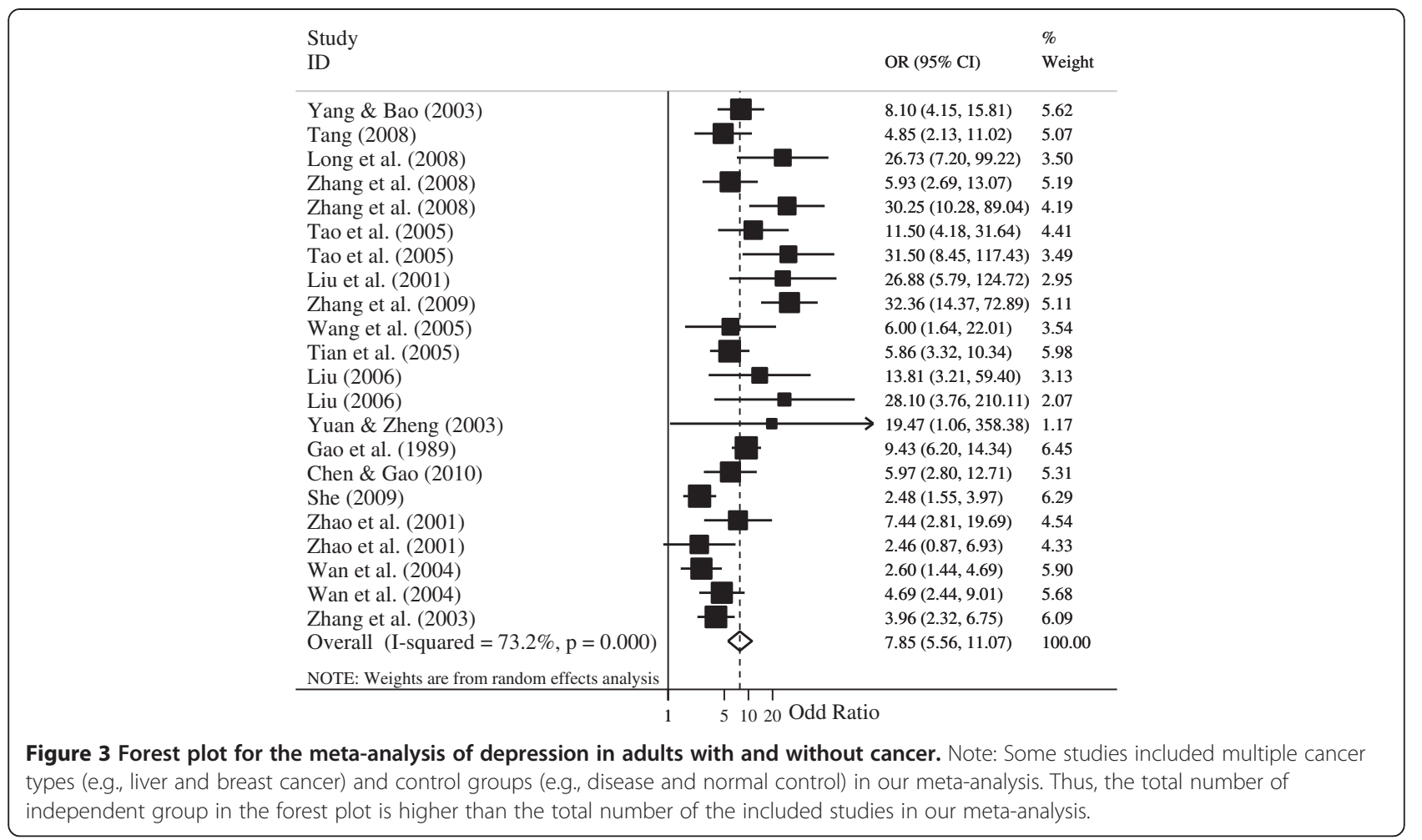

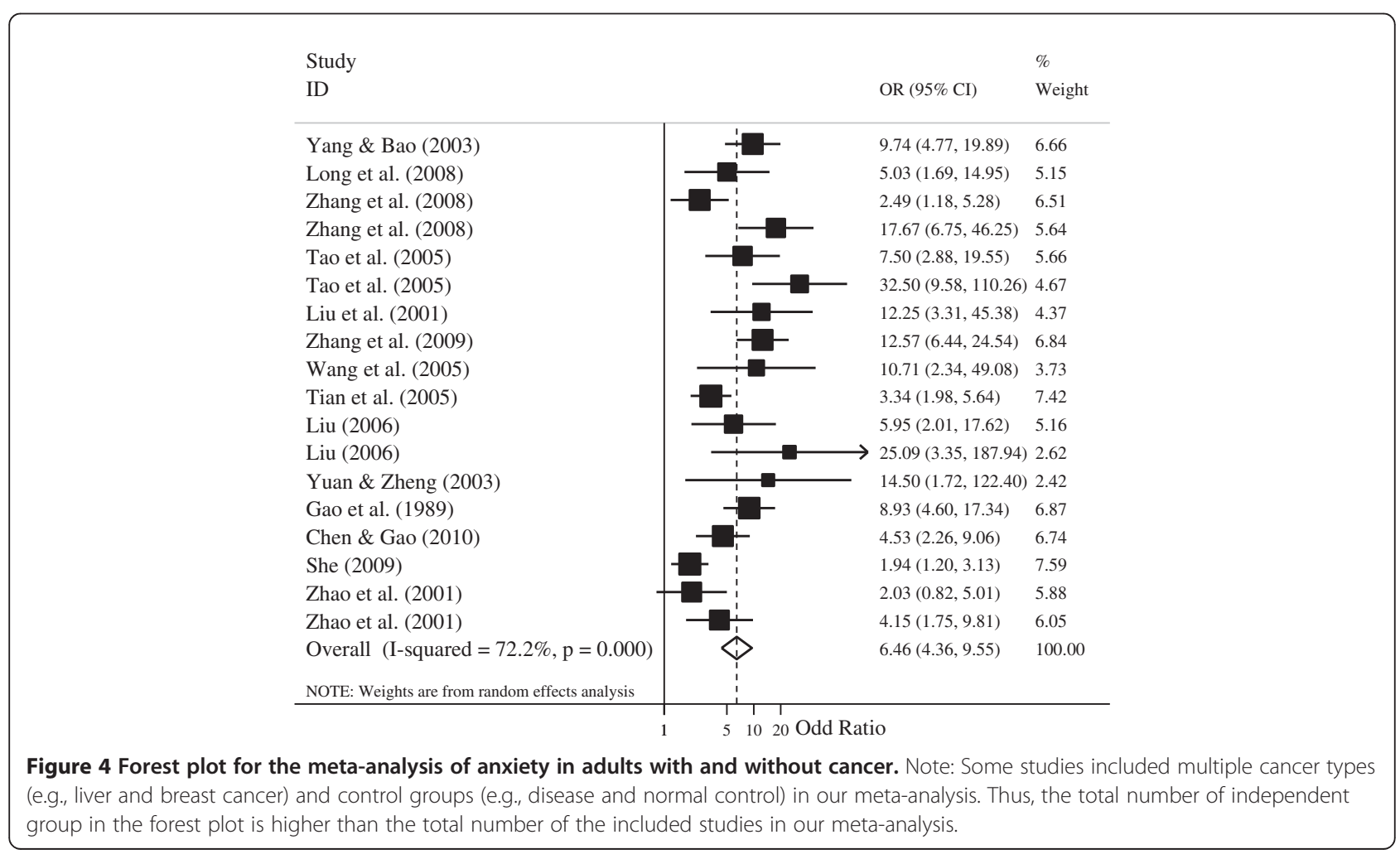


Table 4 Odds ratios of depression and anxiety in adults with and without cancer: subgroup analyses

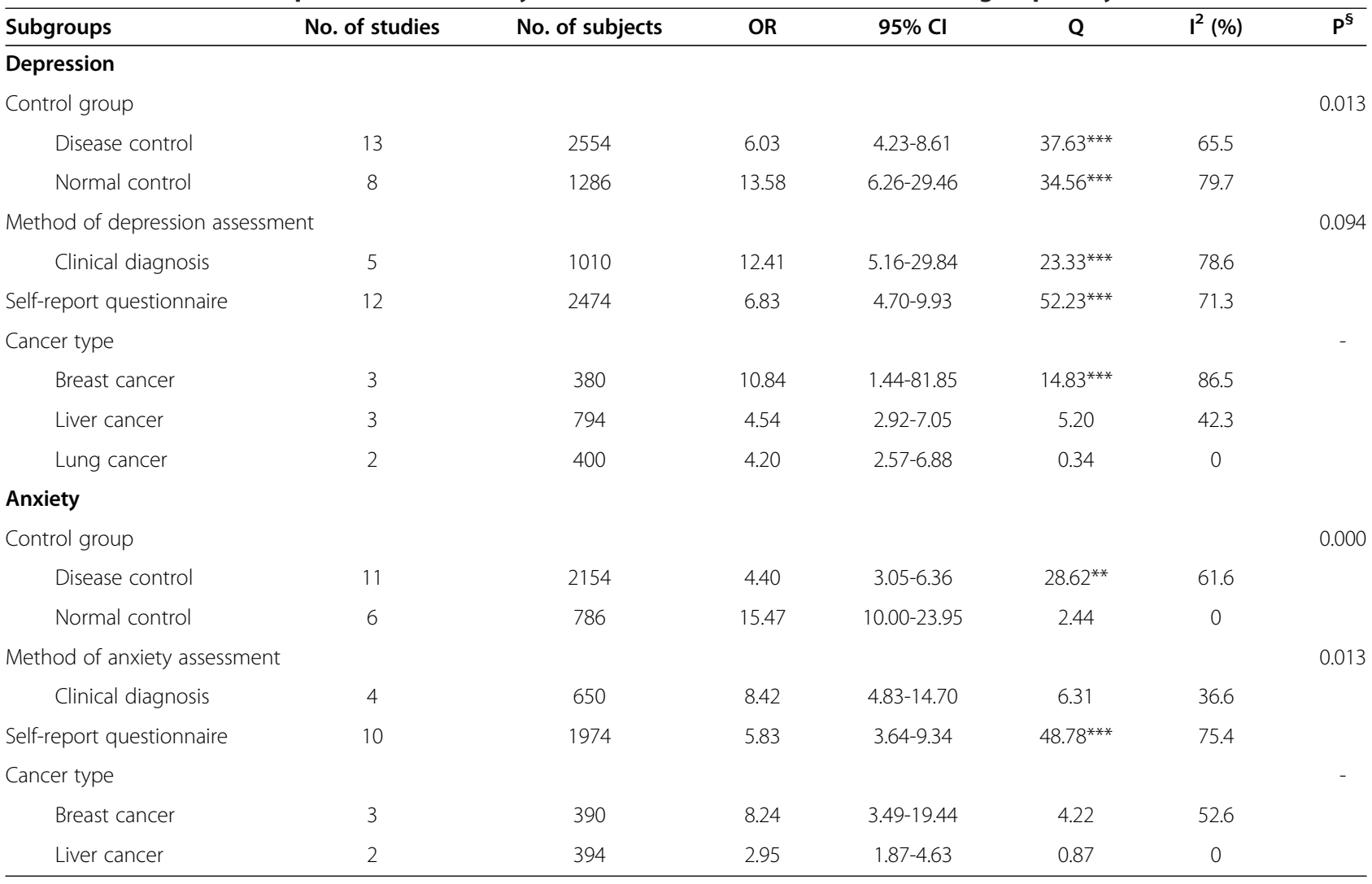

${ }^{* *} p<0.01$.

${ }_{* * *}^{*} p<0.001$.

$\S \mathrm{P}$ of comparison between these subgroups.

Note: The No. of studies per row is based on the independent group of cancer vs. control group. However, some studies included multiple control groups (e.g., disease and normal control). Thus, the total No. of studies per subgroup of control group is higher than the total number of the included studies in our meta-analysis. -, no report.

countries $[17,21]$. This situation should be noticed because comorbid anxiety and depressive disorders tend to have severe symptoms, poorer outcomes and greater use of healthcare resources than those with a single disorder [67]. Meanwhile, the results were slightly higher than some empirical studies assessing the prevalence of depression and anxiety in China [12-14].

We also compared our results with other four relatively comprehensive reviews of depression/anxiety in cancer patients: (1) the review of Pirl reported the prevalence of depression (10\%-25\%) based on 350 English-language literatures published between 1966 and 2001 [68]; (2) Hotopf showed the prevalence of depression for selfreporting questionnaire (29\%) and clinical diagnosis (15\%) based on 46 literatures published before 2000 [9]; (3) Van't Spijker indicated the prevalence of depression (0\%-46\%) and anxiety (0.9\%-49\%) from 58 studies published from 1980 to 1994 [10]; (4) Mitchell reported the prevalence of depression (20.7\%-24.6\%) and anxiety (9.8\%-10.3\%) of 94 interview-based studies published before 2010 [7]. There might be several reasons for the different prevalence. First explanation might be that we only identified 17 eligible studies, but other reviews included at least 46 studies. Our results may be overestimated due to the little studies and high data fluctuation. Second explanation might be that most of the included studies of these reviews are from developed countries which have lower prevalence of mental health problems as compared to developing countries like China [69]. Third explanation might be that depression and anxiety in cancer patients were assessed using different questionnaires. The included studies of these reviews mainly used the Hospital Anxiety and Depression Scale (HADS), but SDS/SAS was the most commonly used in our meta-analysis. Last explanation might be that many studies of these reviews used clinical diagnosis like HRSD/ HRSA, but only five studies of our meta-analysis employed clinical diagnosis method. Some studies indicated that the prevalence of depression and anxiety would be overestimate by self-report questionnaires compared with standardized clinical diagnoses [20,70].

Only reporting the prevalence of depression and anxiety in Chinese cancer patients is not enough, it is important that comparable control groups are involved so that the level of depression and anxiety in cancer patients can be 
reliably and accurately determined. The level of depression $(\mathrm{OR}=7.85,95 \% \mathrm{CI}=5.56-11.07)$ and anxiety $(\mathrm{OR}=6.46$, $95 \% \mathrm{CI}=4.36-9.55)$ were significantly higher in adults with cancer compared with those without. This is the first metaanalysis reporting depression and anxiety in Chinese cancer patients compared with those without. A meta-analytical review also reported depression and anxiety in cancer patients compared with non-cancer group [10], but it yielded an overall effect size of d-value (mean difference), rather than OR/RR.

Through the subgroups analysis of control groups (disease control vs. normal control), cancer patients compared with normal group experienced the higher level of depression/anxiety than them compared with disease group at the 0.05 significance level. More importantly, cancer patients were significantly more depressed and anxious when compared with normal and disease groups, respectively. The majority of studies mainly focused on the psychological disorders in cancer patients and ignored the role and type of control group [7-9,12-14,68]. The results showed that the odds of depression/anxiety were nearly 4-6 times as high in cancer patients, even when compared with disease control including patients with chronic hepatitis [56,58], diabetes [63], tuberculosis [51], benign tumor [62], and other noncancer medical patients $[50,52,54,55,57,60,61,65]$. However, the different level of depression/anxiety between cancer patients and non-cancer populations has been controversial. The study of Reyes-Gibby indicated that respondents with a history of cancer had excess risk for depression $(\mathrm{OR}=1.21 ; 95 \% \mathrm{CI}=1.06-1.37)$ compared to those without [71]. But some studies demonstrated that depression was common not only among cancer patients, but also nearly equally among non-cancer diseases [72,73].

Some studies suggested the discrepancy between clinical diagnosis and self-reports measuring depression/ anxiety among cancer patients $[29,74]$, and indicated the results would be overestimate by self-report questionnaires compared with clinical diagnoses $[20,70]$. Our results seemed to be consistent with the conclusion above. The prevalence of depression/anxiety in cancer patients was higher in self-reports compared with clinical diagnosis, and this situation also occurred in non-cancer group. However, when control groups were involved, we found that a significant smaller OR of anxiety was observed in studies utilizing self-reports compared with clinical diagnosis, although not significantly difference between clinical diagnoses and self-reports of depression. This discrepancy may result from the same reason that these studies only focused on the cancer patients and ignored the control group when different assessment methods of depression and anxiety were used [20,29,70,71]. However, only five and four studies with a combined population of 1010 and 650 were conducted to measure depression/anxiety using clinical diagnoses based on HRSD/HRSA, it was necessary to consider that our results might be influenced by small number of studies.

\section{Implication}

There are several theoretical and practical implications through our meta-analysis. In theory, future studies assessing psychological disorders among cancer patients should include and specify control group. Thus, they could explore the difference levels of depression/anxiety between cancer patients and other populations, including other non-cancer diseases, and on the other hand, a whole new perspective would be provided for researchers on the use of self-reports and clinical diagnosis to assess depression/anxiety in cancer patients when control groups were involved. In practice, first, some studies have shown that it is necessary to evaluate the prevalence of depression and anxiety before any effects can be provided for optimum care among cancer patients and reduction of psychological disorders $[17,18,29]$. The present meta-analysis provided the necessary preparations for oncologists and physicians to treat and manage depression and anxiety in Chinese cancer patients; second, although a brief psychological intervention could promote the quality of life and reduce depression and anxiety among cancer patients [75], oncologists and physicians still remained poor at detecting and treating their cancer patients' psychological problems [76-78]. There might be many reasons for this situation, but one of these reasons could be that oncologists and physicians were unaware of the levels of depression and anxiety in cancer patients. This meta-analysis showed that cancer patients had higher prevalence of depression and anxiety, indicating that depression and anxiety in Chinese cancer patients should be received sufficient attention.

\section{Limitation}

The present meta-analysis had several limitations. First, although some studies demonstrated that depression and anxiety might play a causal role of cancer [25,79], the present meta-analysis was based on cross-sectional studies, which could not determine the causation or temporality of this association between the development of cancer and depression/anxiety. Second, a lot of studies showed that there was a significant relationship between depression/anxiety in cancer patients and age $[18,80]$, cancer type $[10,81,82]$, gender $[83,84]$, income [85] and so on, but our meta-analysis did not provide enough information and number of studies regarding these potential moderating factors. Third, although we employed subgroup analysis to explore potential sources of heterogeneity including control group, methods of depression/anxiety assessment and cancer types, the subgroup analysis could not reduce $\mathrm{I}^{2}$ to $50 \%$ or less in many cases. Fourth, only five and four studies with a combined population of 1010 and 650 
were conducted using HRSD/HRSA to measure clinically significant anxiety and depression. Thus, depression and anxiety in our meta-analysis more often referred to the depressive symptom and anxiety symptom. Fifth, we did not find any international literatures that meet our inclusion and exclusion criteria. It might be because that the international journals require the papers at a high level compared with Chinese journals, and international journals maybe not receive the simple descriptive research. Sixth, as some studies included multiple groups in the meta-analysis, cancer patients or people in control group were included twice when calculating the overall OR of depression/ anxiety. This will overestimate the precision. Finally, the high risk of publication bias is another (and perhaps the most important) limitation.

\section{Conclusions}

We conclude that Chinese adults with cancer had higher prevalence rates of depression and anxiety compared with control group, and the same situation is observed in subgroup analyses. The findings support that the prevalence of depression and anxiety among adults with cancer should receive more attention in Chinese medical settings.

\section{Competing interests}

The authors declare that they have no conflict of interest.

\section{Authors' contributions}

YLY was responsible for conception and design of the review, carried out the literature search, performed data extraction and data analysis, and wrote the manuscript. $L L$ and YW carried out the literature search, performed data extraction, resolved the disagreement, and participated in conception and design of the review. HW, SXY and JNW participated in conception and design of the review, and critically revised the manuscript. LW supervised the data collection, statistical analysis and paper writing. All authors read and approved the final manuscript.

\section{Acknowledgements}

The authors wish to acknowledge the assistance of R Beasley, Professor.

Received: 28 May 2013 Accepted: 31 July 2013

Published: 22 August 2013

\section{References}

1. Seligman MEP, Walker EF, Rosenhan DL: Abnormal psychology. 4th edition. New York: WW Norton \& Company, Inc; 2001.

2. Ali S, Stone MA, Peters JL, Davies MJ, Khunti K: The prevalence of co-morbid depression in adults with type 2 diabetes: a systematic review and meta-analysis. Diabet Med 2006, 23:1165-1173.

3. Cuijpers P, Schoevers RA: Increased mortality in depressive disorders: a review. Curr Psychiatry Rep 2004, 6:430-437.

4. Katon WJ, Lin E, Russo J, Unǔtzer J: Increased medical costs of a population-based sample of depressed elderly patients. Arch Gen Psychiatry 2003, 60:897-903.

5. Hannson L: Quality of life in depression and anxiety. Int Rev Psychiat 2002, 14:185-189.

6. Creed F, Morgan R, Fiddler M, Marshall S, Guthrie E, House A: Depression and anxiety impair health-related quality of life and are associated with increased costs in general medical inpatients. Psychosomatics 2002, 43:302-309.

7. Mitchell AJ, Chan M, Bhatti H, Halton M, Grassi L, Johansen C, Meader N: Prevalence of depression, anxiety, and adjustment disorder in oncological, haematological, and palliative-care settings: A meta-analysis of 94 interview-based studies. Lancet Oncol 2011, 12:160-174.
8. Massie MJ: Prevalence of depression in patients with cancer. J Natl Cancer Inst Monogr 2004, 32:57-71.

9. Hotopf M, Chidgey J, Addington-Hall J, Lan Ly K: Depression in advanced disease: a systematic review. Part 1. Prevalence and case finding. Palliat Med 2002, 16:81-97.

10. Van't Spijker A, Trijsburg RW, Duivenvoorden HJ: Psychological sequelae of cancer diagnosis: a meta-analytical review of 58 studies after 1980. Psychosom Med 1997, 59:280-293.

11. Stark DP, House A: Anxiety in cancer patients. Br J Cancer 2000, 83:1261-1267.

12. Ma YR: An investigation on depression in old cancer patients undergoing chemotherapy and their social supports. Chin Nurs Res 2005, 19:1446-1447 (in China).

13. Gao LP, Weng CS, Zhao H, Yang L, Liu Y, Yuan LJ, Chen DX, Wang L: Correlation between qualities of life and depression, anxiety for cancer patients. Chinese JRehabil Theory Pract 2006, 12:192-193 (in China).

14. Li Z, Xu HY, Bao JJ, Tang YY: An investigation of emotional disorder in cancer inpatients. J Clinical Psychosom Dis 2007, 13:250-251 (in China).

15. Capuron L, Ravaud A, Dantzer R: Early depressive symptoms in cancer patients receiving interleukin 2 and/or interferon alfa-2b therapy. $J$ Clin Oncol 2000, 18:2143-2151.

16. Zhang GZ, Yin ZQ, You XH, Dong YJ: A study on anxiety and depression of cancer patients undergoing radiotherapy and chemotherapy in the initial stage and their coping state. Chinese Nurs Res 2007, 21:2852-2584 (in China).

17. Lloyd-Williams M: Difficulties in diagnosing and treating depression in the terminally ill cancer patient. Postgrad Med J 2000, 76:555-558.

18. Jadoon NA, Munir W, Shahzad MA, Choudhry ZS: Assessment of depression and anxiety in adult cancer outpatients: a cross-sectional study. BioMed Central 2010, 10:1471-2407.

19. Ashbury FD, Findlay H, Reynolds B, McKerracher K: A Canadian survey of cancer patients' experiences: Are their needs being met? J Pain Symptom Manage 1998, 16:298-306.

20. Stark D, Kiely M, Smith A, Velikova G, House A, Selby P: Anxiety disorders in cancer patients: their nature, associations, and relation to quality of life. J Clin Oncol 2002, 20:3137-3148.

21. Mystakidou K, Tsilika E, Parpa E, Katsouda E, Galanos A, Vlahos L: Assessment of anxiety and depression in advanced cancer patients and their relationship with quality of life. Qual Life Res 2005, 14:1825-1833.

22. House A, Stark D: ABC of psychological medicine: anxiety in medical patients. BMJ 2002, 325:207-209.

23. Stommel M, Given BA, Given CW: Depression and functional status as predictors of death among cancer patients. Cancer 2002, 94:2719-2727.

24. Pinquart $M$, Duberstein PR: Depression and cancer mortality: a meta-analysis. Psychol Med 2010, 40:1797-1810.

25. Satin JR, Linden W, Phillips MJ: Depression as a predictor of disease progression and mortality in cancer patients: a meta-analysis. Cancer 2009, 115:5349-5361.

26. Yang RT, Huang XW: Meta-analysis of the effects of psychological intervention on physical and mental condition in cancer patients. China Caner 2009, 18:187-190 (in China).

27. Jiang $X M, M i D H$, Wang $H Q$, Zhang L: Mental intervention for cancer patients with depression: a systematic review of randomized controlled trials. Chin J Evid-based Med 2010, 10:352-355 (in China).

28. Osborn RL, Demoncada AC, Feuerstein M: Psychosocial interventions for depression, anxiety, and quality of life in cancer survivors: meta-analyses. Int J Psych Med 2006, 36:13-34.

29. Jacobsen PB, Jim HS: Psychosocial interventions for anxiety and depression in cancer patients: achievements and challenges. CA-Cancer J Clin 2008, 58:214-230.

30. Uitterhoeve RJ, Vernooy M, Litjens M, Potting K, Bensing J, De Mulder P, Van Achterberg T: Psychosocial interventions for patients with advanced cancer-a systematic review of the literature. Br J Cancer 2004, 91:1050-1062.

31. Dai M, Ren JS, Li N, Li Q, Yang L, Chen YH: Estimation and prediction on cancer related incidence and mortality in China, 2008. Chin J Epidemiol 2012, 33:57-61 (in China).

32. Fann JR, Thomas-Rich AM, Katon WJ, Cowley D, Pepping M, McGregor BA, Gralow J: Major depression after breast cancer: a review of epidemiology and treatment. Gen Hosp Psychiatry 2008, 30:112-126.

33. Reich M, Lesur A, Perdrizet-Chevallier C: Depression, quality of life and breast cancer: a review of the literature. Breast Cancer Res Treat 2008 110:9-17. 
34. American Psychiatric Association: Diagnostic and statistical manual of mental disorders: DSM-IV-TR. Washington, DC: American Psychiatric Pub; 2000.

35. Chen YF: Chinese classification of mental disorders (CCMD-3): towards integration in international classification. Psychopathology 2002, 35:171-175.

36. Hamilton M: The assessment of anxiety states by rating. $\mathrm{Br} J$ Med Psychol 1959, 32:50-55.

37. Hamilton M: A rating scale for depression. J Neurol Neurosurg Psychiatry 1960, 23:55-62.

38. Stroup DF, Berlin JA, Morton SC, Olkin I, Williamson GD, Rennie D, Moher D, Becker BJ, Sipe TN, Thacker SB: Meta-analysis of observational studies in epidemiology: a proposal for reporting. JAMA 2000, 283:2008-2012.

39. Wells GA, Shea B, O'Connell D, Peterson J, Welch V, Losos M, Tugwell P: 2006 Newcastle-Ottawa scale; 2006. http://www.lri.ca/programs/ clinical_epidemiology/oxford.htm.

40. Der Simonian R, Laird N: Meta-analysis in clinical trials. Controlled Clin Trials 1986, 7:177-188

41. Whitehead A, Whitehead J: A general parametric approach to the meta-analysis of randomised clinical trials. Stat Med 1991, 10:1665-1677.

42. Parzen M, Lipsitz S, Ibrahim J, Klar N: An estimate of the odds ratio that always exists. J Comput Graph Stat 2002, 11:420-436

43. Hedges LV, Olkin I: Statistical methods for meta-analysis. San Diego, CA Academic; 1985

44. Borenstein M, Hedges L, Higgins J, Rothstein H: Introduction to meta-analysis. Oxford: Wiley; 2009

45. Higgins JPT, Thompson SG, Deeks JJ, Altman DG: Measuring inconsistency in meta-analyses. BMJ 2003, 327:557-560

46. Funnel plot. http://en.wikipedia.org/wiki/Funnel_plot.

47. Terrin N, Schmid CH, Lau J: In an empirical evaluation of the funnel plot, researchers could not visually identify publication bias. J Clin Epidemiol 2005, 58:894-901.

48. Begg CB, Mazumdar M: Operating characteristics of a rank correlation test for publication bias. Biometrics 1994, 50:1088-1101.

49. Egger M, Davey Smith G, Schneider M, Minder C: Bias in meta-analysis detected by a simple, graphical test. BMJ 1997, 315:629-634.

50. Chen ZJ, Gao YL: The analysis of esophageal cancer patients with emotional disorder. J Basic and Clinical Oncol 2010, 23:268-269.

51. Gao BL, Yang LL, Li H: Life event, emotional distress and human cancer. Chin Ment Heal J 1989, 3:1-10.

52. Liu ZJ: A correlative study of the psychosocial factors of emotional disorder and quality of life in cancer patients. Master's Thesis. Soochow University: Psychiatry and Mental Health Department; 2006.

53. Liu HX, Xue RL, Liu XQ: An investigation of psychological status in cancer patients. Health Psychol J 2001, 9:139-140.

54. Long SL, Yang F, Wu HH: Investigation of psychological status in advanced cancer patients and nursing strategy. J Pract Med Tech 2008, 15:4703-4705.

55. Tang JQ: Investigation of the depression states in cancer patients and nursing intervention. Guide of Chinese Med 2008, 6:69-70.

56. Tao J, Ye MZ, Yi HQ, Wen SL, Wang XL: Psychosomatic status and psychological intervention on cancer patients. J Sun Yat-Sen University (Med Sci) 2005, 26:583-568

57. Tian YS, Zhang QH, Zhu Y: Investigation of the mental characteristics in patients suffering from hepatocarcinoma. Modern Med Health 2005, 21:3204-3205

58. Wan LH, Sun HF, Mo HX, Li T, He HH: A survey of depressive symptoms in patients with primary liver cancer. Nanfang J Nurs 2004, 11:50-51.

59. Wang $H$, Zhu H, Li P, Wang XW: Study on the change and correlation between psychology and immunity function in lung cancer patients. Chinese J Behav Med Sci 2005, 14:320-321.

60. She RM: An investigation of mood disorders of in patients with malignant tumor and its influential factors. Master's thesis. Central South University: Medical Oncology Department; 2009.

61. Yang HM, Bao WQ: A survey of reply pattern towards feeling disturbances of cancer patients. Chin Nurs Res 2003, 17:686-687.

62. Yuan WQ, Zheng JM: Investigation of psychological status in operation of breast cancer patients and nursing strategy. J Hangzhou Med College 2004, 24:132.

63. Zhang PX, Zhao YN, Wang CY: Study on the psychological status of 60 patients with carcinomas. Chin Clin Oncol 2008, 13:917-919.

64. Zhang LY, Shang WJ, Dai ZX, Wang JH, Wang ZZ: Study of anxiety and depression among breast cancer patients and psychological ethical intervention. Chinese Med Ethics 2009, 22:23-30.
65. Zhao WL, He J, Wu JP, Zhu MJ, Fan SJ, Li MY, Shi HQ, Liang HY: An investigated analysis of emotional disorder in patients with hepatic cancer and breast cancer. Guangxi Med J 2001, 23:1019-1021.

66. Zhang LH, Bai L, Huang DF, He P: Clinical characteristics and related factors of depression in patients with lung cancer. Chinese J Clinic Rehabil 2003, 7:3343-3345.

67. Hirschfeld RMA: Comorbidity of major depression and anxiety disorders: recognition and management in primary care. Primary Care Companion J Clin Psychiatry 2001, 3:244-254.

68. Pirl WF: Evidence report on the occurrence, assessment, and treatment of depression in cancer patients. J Natl Cancer Inst Monogr 2004, 32:32-39.

69. Demyttenaere K, Bruffaerts R, Posada-Villa J, Gasquet I, Kovess V, Lepine JP, Angermeyer MC, Bernert S, de Girolamo G, Morosini P, Polidori G, Kikkawa T, Kawakami N, Ono Y, Takeshima T, Uda H, Karam EG, Fayyad JA, Karam AN, Mneimneh ZN, Medina-Mora ME, Borges G, Lara C, de Graaf R, Ormel J, Gureje $O$, Shen $Y$, Huang $Y$, Zhang M, Alonso J, et al: Prevalence, severity, and unmet need for treatment of mental disorders in the World Health Organization World Mental Health Surveys. JAMA 2004, 291:2581-2590.

70. Hall A, Ahearn R, Fallowfield L: Are we using appropriate self-report questionnaires for detecting anxiety and depression in women with early breast cancer? Eur J Cancer 1999, 35:79-85.

71. Reyes-Gibby CC, Aday LA, Anderson KO, Mendoza TR, Cleeland CS: Pain, depression, and fatigue in community-dwelling adults with and without a history of cancer. J Pain Symptom Manage 2006, 32:118-128.

72. Solano JP, Gomes B, Higginson IJ: A comparison of symptom prevalence in far advanced cancer, AIDS, heart disease, chronic obstructive pulmonary disease and renal disease. J Pain Symptom Manage 2006, 31:58-69.

73. Bekelman DB, Rumsfeld JS, Havranek EP, Yamashita TE, Hutt E, Gottlieb SH, Dy SM, Kutner JS: Symptom burden, depression, and spiritual well-being: a comparison of heart failure and advanced cancer patients. J Gen Intern Med 2009, 24:592-598.

74. Nordin K, Berglund G, Glimelius B, Sjoden PO: Predicting anxiety and depression among cancer patients: a clinical model. Eur J Cancer 2001 37:376-384

75. Pitceathly C, Maguire P, Fletcher I, Parle M, Tomenson B, Creed F: Can a brief psychological intervention prevent anxiety or depressive disorders in cancer patients? A randomised controlled trial. Ann Oncol 2009, 20:928-934

76. Fallowfield L, Ratcliffe D, Jenkins V, Saul J: Psychiatric morbidity and its recognition by doctors in patients with cancer. Br J Cancer 2001 84:1011-1015

77. Keller M, Sommerfeldt S, Fischer C, Knight L, Riesbeck M, Löwe B, Herfarth C, Lehnert T: Recognition of distress and psychiatric morbidity in cancer patients: a multi-method approach. Ann Oncol 2004, 15:1243-1249.

78. Singer $\mathrm{S}$, Bringmann $H$, Hauss J, Kortmann RD, Köhler U, Krauss O, Schwarz R: Prevalence of concomitant psychiatric disorders and the desire for psychosocial help in patients with malignant tumors in an acute hospital. Dtsch Med Wochenschr 2007, 132:2071-2076.

79. Thomas C, Medden F, Jehu D: Psychological effects of stomas: a. Factor influencing outcome. J Psychosom Res 1987, 31:317-323.

80. Tavoli A, Mohagheghi MA, Montazeri A, Roshan R, Tavoli Z, Omidvari S: Anxiety and depression in patients with gastrointestinal cancer: does knowledge of cancer diagnosis matter? BMC Gastroenterol 2007, 7:28.

81. Brintzenhofe-Szoc KM, Levin TT, Li Y, Kissane DW, Zabora JR: Mixed anxiety/ depression symptoms in a large cancer cohort: prevalence by cancer type. Psychosomatics 2009, 50:383-391.

82. Fischer DJ, Villines D, Kim YO, Epstein JB, Wilkie DJ: Anxiety, depression and pain: differences by primary cancer. Support Care Cancer 2010 18:801-810.

83. Miaskowski C: Gender differences in pain, fatigue, and depression in patients with cancer. J Natl Cancer Inst Monogr 2004, 32:139-143.

84. Deflorio M, Masie MJ: Review of depression in cancer: gender differences. Depression 1995, 3:66-80

85. Chen X, Zheng Y, Zheng W, Gu K, Chen Z, Lu W, Shu XO: Prevalence of depression and its related factors among Chinese women with breast cancer. Acta Oncol 2009, 48:1128-1136.

doi:10.1186/1471-2407-13-393

Cite this article as: Yang et al:: The prevalence of depression and anxiety among Chinese adults with cancer: a systematic review and meta-analysis. BMC Cancer 2013 13:393. 